\title{
Comprensión jurídico-procesal de la seguridad social en salud
}

\section{Legal and procedural understanding of the social security in health Entendimento jurídico-processual da seguridade social na saúde}

\begin{abstract}
RESUMO
Ápos a realização de um processo de pesquisa de caráter científico surge os produtos ou resultados da pesquisa, por isso no presente documento físico são mostrados as análises, desenvolvimento e conclusões sobre o sistema de seguridade social na saúde, no seu estudo e compreensão processual onde é garantizado direitos e deveres dos membros e contribuidores, sejamestes infringidos ou dentro da operativide propria do sistema. De modo que cada método científico exige de um recorrido que permita se aproximar o objeto com o assunto da pesquisa. Esta parte precisou de uma pesquisa no cual foi necessário a abordagem hermenêutica documental. Foi adquirido uma informação detalhada sistemática em quanto às clasificações ou taxonomia dos procedimentos administrativos e judiciais, ao igual que as escolas processuais que têm como objeto as exploração da natureza dos processos do sistema da saúde.
\end{abstract}

PALAVRAS-CHAVES

Processos, Procedimientos, Garantia, Saúde, Sistema, Seguridade social.

\section{RESUMEN}

Luego de realizar un proceso investigativo de carácter científico se suscitan los productos o resultados de investigación, es por ello que en el presente documento físico se mostrarán los análisis, desarrollos y conclusiones acerca del Sistema de Seguridad Social en Salud, en su estudio y entendimiento procesal y procedimental donde se garantizan derechos y deberes de los afiliados y cotizantes, sean estos vulnerados, o dentro de la operatividad propia del sistema. Es así que cada método científico requiere de un recorrido que permita acercar el objeto con el sujeto de investigación. A este respecto, en esta investigación fue necesario el enfoque hermenéutico documental. Se obtuvo una información detallada y sistemática en cuanto a la clasificación o taxonomía de los procedimientos administrativos y judiciales, al igual que las escuelas procesales que tienen por objeto la explicación de la naturaleza de los procesos del sistema de salud.

PALABRAS CLAVE

Procesos, Procedimientos, Garantismo, Salud, Sistema, Seguridad social.

\section{ABSTRACT}

After conducting a scientific research process products or research result arise, which is why in this physical document, previews, analysis, contributions, synthesis, development and conclusions about the system of social health are displayed, in their study and understanding of procedural and procedural where rights and duties of members and contributors of this is guaranteed, whether they violated or within the actual operation of the system. So that every scientific method requires a pattern to ensure that bring the object with the research subject, in this research the documentary hermeneutical necessary, detailed and systematic information was obtained regarding the classification or taxonomy of administrative and judicial procedures as well as procedural schools aimed at explaining the nature of the processes of the health system.

\section{KEYWORDS}

Processes, Procedures, Guarantees, Health, Social Security system.

\section{JORGE LUIS RESTREPO PIMIENTA}

Abogado. Especialista en Educación, Derecho Constitucional, Derecho Laboral y Seguridad Social. Magíster en Derecho, candidato a Doctor en Derecho, par académico de COLCIENCIAS, CNA y CONACES. Investigador asociado, docente Universidad del Atlántico y Universidad Libre. jorluisrestrepo@yahoo.es

EVELIA MARÍA MOLINA IMITOLA

Abogada. Especialista en Derecho Laboral y magíster en Derecho. Funcionaria Judicial jurisdicción laboral y de la seguridad social. Docente de la Universidad del Atlántico y Universidad de la Costa, CUC. evemolm31@ @otmail.com 


\section{INTRODUCCIÓN}

El presente producto de investigación pretende reseñar una situación o realidad específica dentro del sistema de salud de carácter jurídico-procesal para restablecer derechos y garantías vulneradas o conquistas de estos dentro de la operatividad del sistema.

En este orden de ideas, es válido anotar que la administración de justicia o la jurisdicción está cimentada en los principios y definición del Estado Social de Derecho. Es por ello que la exclusividad, obligatoriedad, coordinación, control, manejo y dirección de los procesos judiciales y administrativos están bajo la potestad del Estado, la cual opera por medio de los funcionarios judiciales y del Ejecutivo que están investidos de jurisdicción y poseen competencia.

Con lo anterior se puede decir que la competencia es una capacidad de conocimiento y de especialidad para resolver problemas, hechos y situaciones de la cotidianidad y del tráfico legal de los hombres en sociedad organizada e instituida; es de resaltar también, en esta consecución, que toda competencia goza de jurisdicción. Dentro de la epísteme conceptual, la competencia es la especie de la jurisdicción.

El Sistema de Seguridad Social en Salud es una estructura organizada compuesta por normas, instituciones y procedimientos, donde se trazan garantías que cubren, protegen o se intenta reparar contingencias de enfermedad y maternidad, que entre otras cosas son hechos biológicos futuros y ciertos, por medio de las prestaciones asistenciales que se materializan a partir del plan obligatorio en salud y los planes adicionales y económicos como licencia de maternidad, paternidad e incapacidad.

En materia de competencia de los procedimientos judiciales y administrativos de la seguridad social en salud, se encuentra una anomalía reflejada en la realidad social, constitucional, política y de justicia garante, dado que el conflicto de competencia -por falta de interpretación de la norma, de compresión de la especialidad de los juzgados laborales y de la seguridad social, administrativos y las Superintendencias de Salud- Ilevan a afectar la salud desde sus diversas connotaciones como condición y naturaleza del ser humano, en su matiz de derecho fundamental, política pública, servicio esencial, la prestación asistencial y demás aspectos sociales relevantes.

Continuando con lo anterior, los procesos judiciales y administrativos en seguridad social en salud -desde la Carta Política de 1991, la Ley 712 de 2001, Ley 1122 de 2007 y Ley 1437 de 2011- se clasifican en procesos ordinarios, ejecutivos, acción de control, solicitudes, quejas, y la acción constitucional de tutela, que buscan desde su dimensión ontológica, axiológica y normativa hacer efectivos o restablecer los derechos vulnerados, conquistar prestaciones, reparar daños y conceder prestaciones asistenciales y económicas, aspectos que en un trasfondo se encuentran 
en las garantías y derechos humanos de los asociados.

El tema de la compresión del derecho procesal de la seguridad social en salud tiene por objeto hacer un constructo conceptual acerca de este como disciplina jurídica y la vez mostrar alternativas de solución a las diferentes controversias y conflictos del administrador, prestador con referente a los usuarios y clientes del sistema en el sentido de cumplimiento de derechos y deberes del sistema de salud.

\section{METODOLOGÍA}

Para mostrar los resultados investigativos a través de presente artículo científico se hizo uso de metodología de la investigación cualitativa, armonizada y direccionada por el tipo hermenéutico documental, aplicando técnicas pertinentes tales como la observación y el análisis documental con el fin de encontrar el objeto y objetivo propuesto en dicho proceso investigativo: estructurar la compresión teórica, práctica y programática del derecho procesal a la seguridad social en un contexto de crisis, controversias y conflictos que se generan en la operatividad del sistema de salud con respecto a los derechos fundamentales.

Asimismo, se realizará un esbozo conceptual, estructural, sistémico relacionado con los modelos procesales, garantismos constitucionales, pensamiento comprensivo histórico de la seguridad social y la salud, y su diversidad clasificatoria de procedimientos en lo administrativo y judicial.
1.1 Aproximación de la seguridad social en salud. Dimensión general

La seguridad social en salud es una disciplina, conjunto de garantías, un sistema estructural compuesto por diversas instituciones, normas, procedimientos y actores sociales, los cuales se ven en contantes controversias, tensiones, choques y circunstancias de diferencias prestacionales en cuanto a lo asistencial como a lo económico. De esta manera, la compresión del derecho procesal a la seguridad social en salud se genera dentro de un sistema complejo regulado.

Asimismo, en cuanto aproximaciones de tipo fidedigno, cabe manifestar que para efectos de determinar los orígenes de la seguridad social y cuáles son los procesos y procedimientos llevados y tramitados en ella para resolver conflictos de salud, enfermedad, maternidad y paternidad, cabe, entonces, hablar del comienzo histórico institucional de la seguridad social. A este respecto, hay que referirse al perfeccionamiento de las categorías a medida que han surgido en la sociedad para la complacencia de las necesidades sociales individuales y colectivas dentro de la fragilidad de los seres humanos.

Por eso es necesario mencionar los inicios y antecedentes de la noción auténtica de seguridad social, partiendo de una perspectiva epistemológica conceptual que indague los procedimientos actuales reglados y normados para abordar controversias en materia de prestaciones asistenciales y económicas 
establecidas en el Sistema Nacional de Salud. Ahora bien, se tratará de esbozar, según el tratadista Arenas Monsalve (2009, pp. 1758), un bosquejo histórico de las instituciones que dieron formación al concepto clásico y actual de seguridad social, que describe así:

Los Collegia Romanos constituyen un antecedente de la Seguridad Social, en cuanto surgieron como asociaciones corporativas de trabajadores libres, que tenían fines religiosos y de ayuda mutua. Pero estas instituciones, fuera de las ventajas económicas, no tenían otra finalidad que el reconocimiento de auxilios funerarios y en ocasiones, de limitadas prestaciones económicas para huérfanos y viudas (Rengifo O, 1989).

Se analiza, entonces, que esta institución de la época romana desarrolla en concreto precarias actividades de seguridad social, que estaban más bien enfocadas a fines sociales o colectivos, como el pago eventual de prestaciones económicas y auxilios mortuorios. Prosigue el comentarista refiriendo:

Las Guildas surgieron en los países germánicos y anglosajones con el carácter de asociaciones de defensa y asistencia mutua, unidos a una fraternidad de combate y armas. Es especial, las guildas de mercaderes y artesanos tienen finalidades de ayuda mutua: socorren a sus miembros enfermos y en caso de muerte se encargande educar a los hijos huérfanos; si alguien de la guilda cae en la miseria, reci- be un apoyo económico durante su vida (1989).

Esta variante de la institución romana da un poco más de evidencias de actividad en materia de seguridad social, porque se refleja en que su objetivo principal era la asistencia social a enfermos, a huérfanos y al subsidio de personas con precariedad económica. Se refiere así a las cofradías:

Las Cofradías o hermandades fueron instituciones de ayuda mutua y religiosa que surgieron principalmente en España, tenían por finalidad ofrecer a sus miembros auxilios por enfermedad, asistencia médica y atención hospitalaria en sus propios hospitales; otorgaban también auxilios por invalidez, vejez, accidente, muerte y otros. Las cofradías formaron su organización autónoma, con régimen administrativo propio y con criterios bastante similares al mutualismo. A finales del siglo XVIII había en España cerca de veinte mil cofradías, sin embargo, fueron controladas y aun perseguidas por buscar únicamente sus privilegios y contribuir a encarecer la vida.

Según criterio del autor de este artículo, las cofradías son la primera institución que históricamente se ocupó, así sea en forma precaria, de aspectos determinantes de la seguridad social que hoy son de vital importancia en el concepto moderno de la misma. Reproduciendo textualmente palabras del mismo tratadista, se aborda el tema de los 
auxilios por enfermedad, asistencia médica y atención hospitalaria en sus propios hospitales; otorgaba también auxilios por invalidez, vejez, accidente, muerte y otros. Luego aparecen las corporaciones de oficios:

Las llamadas corporaciones de oficios fueron instituciones que se crearon dentro del orden jerárquico y estamental de la edad media, organizadas por los artesanos y comerciantes, con la finalidad de proteger a sus miembros y garantizar la calidad de sus productos y servicios. Los talleres de artesanos eran jerarquizados y sujetos a rígidas normas. La importancia de las corporaciones de oficios desde el punto de vista de las prestaciones, estriba en que los artesanos de un mismo oficio organizaban cofradías con la finalidad de atender la enfermedad, la desocupación y la incapacidad. Avanzado el tiempo, las corporaciones entraron en crisis, la economía y la política sufrieron grandes transformaciones, hasta que en 1776 en Francia, el famoso Edicto de Turgot ordenó la supresión de las corporaciones e inauguró la libertad de trabajo y con ella el inicio del capitalismo (Arenas Monsalve, 2009, p. 18).

Así como las cofradías, las corporaciones de oficios desde el punto de seguridad social, trabajaron el aspecto prestacional, enfocadas especialmente en temas tan puntuales como la enfermedad, la incapacidad generada como consecuencia de la misma y el desempleo o desocupación o inactividad laboral, hechos que aún en el desarrollo del Derecho Laboral moderno, nacional e internacional, resultan vitales para la implementación de los derechos laborales de los trabajadores.

Cabe concluir que, en esencia, los Collegia Romanos trabajaron el tema de eventuales prestaciones económicas y auxilios por muerte; las Guildas se enfocaron a la asistencia social para los enfermos, los huérfanos y a subsidiar a personas con dificultades económicas; las Cofradías se ocuparon de los auxilios por enfermedad, asistencia médica y atención hospitalaria invalidez, vejez, accidente, muerte y otros y posteriormente las Corporaciones de oficios, de la enfermedad, la incapacidad y la inactividad laboral, siendo en conjunto las instituciones antiguas que sentaron las bases de la seguridad social moderna, en la medida que son aspectos que hoy en día han desarrollado y son materia tanto de estudio como de evolución normativa y jurisprudencia a nivel mundial, por los Estados, organismos legislativos y organizaciones no gubernamentales que se ocupan de la defensa de los derechos laborales.

De este modo, en la actualidad colombiana la seguridad social en salud está compuesta por instituciones de orden de dirección, inspección y vigilancia, las cuales en muchas circunstancias hacen de juzgador para restablecer derechos fundamentales vulnerados; las segundas comportan la de administración y financiación, las cuales son objeto de controversias con los clientes o los usuarios, y por último las prestadoras, donde también 
es usual encontrar casos de responsabilidad civil en salud; es allí donde va operar el derecho procesal de la seguridad social en salud.

\subsection{El derecho procesal de la seguridad so- cial en salud en la realidad colombiana}

Antes de entrar en consideración frente a los antecedentes históricos de la seguridad social en salud, cabe comentar que esta ha ido evolucionando desde el asistencialismo, manifestándose de tres formas: la familiar, la pública y la privada. Ahora, en orden evolucionista, surge en el marco de procesos de previsión, los cuales estaban compuestos por el mutualismo, el ahorro y los seguros privados.

Ahora bien, para determinar tiempos demarcados frente a los orígenes y desarrollo constitucional, normativo, procedimental y conceptual de la seguridad social en salud en Colombia, según Arenas Monsalve (2009), se hace necesario mostrar las vicisitudes y transformaciones periódicas a través de las diferentes fases señaladas:

Primera fase. Se inicia con la constitución de 1886 hasta mediados de 1.950, y en donde prevé lo que se puede denominar como higienista. (MINSALUD Y DNP, 1990). En esta Segunda fase la provisión se limitaba a atender aspectos de carácter sanitario, mientras que la atención preventiva y curativa en Salud tenía que ser atendida por los propios usuarios o por algunas instituciones religiosas o de caridad. Se crea posteriormente una forma de proteger la salud de los empleados públicos y para 1946, se crea el Instituto Colombiano de Seguros sociales, que atendía a los trabajadores del sector privado formal. La Tercera Fase arranca desde 1970 hasta 1989 caracterizado, por la creación del Sistema Nacional de Salud, bajo el esquema de subsidio a la oferta, teniendo en cuenta que los recursos del gobierno Central para la salud eran transferidos a la red instituciones públicas hospitalarias.

A partir de la Ley 100 de 1993, se crea el Sistema de Seguridad Social en Salud, tipos de servicios, grados de complejidad y niveles de atención, reglamenta la carrera administrativa del sector salud, red de hospitales públicos, el régimen de referencia y contrarreferencia. Este es un tiempo lleno de avances y conflictos económicos, sociales, culturales y políticos, dado a que la apertura económica inicia en los años noventa. Aunque existía un estatuto laboral específico del sector salud recién reglamentado por la ley en mención, se creaba a su vez la Ley 50 de 1990, la cual permitía la intermediación laboral o el fenómeno de la deslaboralización, lo cual traía consigo el sacrificio de la calidad y la eficiencia en la prestación de los servicios de salud por parte del Estado y los particulares, comprendido como derecho, garantía y servicio público esencial.

En este orden cronológico de acontecimientos históricos en materia de seguridad social en salud, es pertinente resaltar la génesis 
a la luz de la Constitución Política de 1991, donde la seguridad social aparece como un conjunto de derechos sociales, económicos y culturales que posteriormente la jurisprudencia constitucional los define como fundamentales por conexidad. Así, el nuevo modelo de Estado denominado Social de Derecho supone un cambio en la concepción de los servicios de salud considerados como de asistencia pública, para posteriormente ser un derecho irrenunciable, universal, imprescriptible, general, pluralista, diverso, complejo, prestacional y sistémico.

La Ley 100 de 1993 crea el Sistema de Seguridad Social en Salud. En el libro segundo establece dos regímenes: contributivo y subsidiado. Esta ley estipula además las prestaciones asistenciales a través del plan obligatorio de salud compuesto por el plan de atención básica, plan de atención materno-infantil, hospitalización, atención inicial de urgencias, accidentes de tránsito y catástrofes naturales y el plan adicional de salud integrado por las pólizas de salud y la medicina prepagada y en cuanto a prestaciones económicas las licencias de maternidad y la incapacidad.

Por su parte, cabe mencionar el Decreto 806 de 1998, el cual reglamenta las prestaciones asistenciales y económicas al igual que los procedimientos para adquirirlas dentro del Sistema de Seguridad Social en Salud, es decir, se contemplan los lineamientos de los procedimientos administrativos ante las EPS y EPSS, en cada una de sus etapas, para restablecer y conceder derechos establecidos en los principios y el régimen de beneficios (Legis, 2009, p. 759).

En este orden de evolución jurídico-normativa el gobierno nacional expide el Decreto 1011 de 2006, donde se establece el Sistema Obligatorio de Garantía de Calidad de la Atención de Salud del Sistema General de Seguridad Social en Salud. Dicho decreto aborda además los procedimientos administrativos internos y externos acerca del Sistema Único de Acreditación, Sistema de Información para la Calidad y la Auditoría para el Mejoramiento de la Calidad de la Atención de Salud (Delgado Bernal, 2012, pp. 566-567).

Ahora bien, en el Estado colombiano suscita, por la necesidad y realidad existente de cobertura y universalidad, la Ley 1122 de 2007, que reforma al Sistema de Seguridad Social en Salud al crearse las EPSS, se define el concepto de salud pública, se estructura el plan territorial de salud y se le dan funciones jurisdiccionales a la Superintendencia Nacional de Salud formando esto parte del derecho procesal de la seguridad social en salud; permitiendo agilizar los trámites, solicitudes y quejas ante las EPS, IPS y ESE, frente a la eficiencia, calidad y eficacia de los servicios de salud, con lo cual se busca garantizar el derecho a la salud desde su accesibilidad, cobertura, universalidad y oportunidad para toda la población (Cortés González, 2011, p. 38).

Dentro de este marco normativo, desde la historia judicial y procesal también aparece 
la Ley 712 de 2001, que reforma al Código Procesal Laboral, cambia la denominación por Código Procesal del Trabajo y la Seguridad Social, donde los jueces adquieren esta responsabilidad o competencia judicial dentro de su jurisdicción de resolver o dirimir conflictos de seguridad social en salud, a causa de las afiliaciones, trámites, cotizaciones, prestaciones de los servicios salud dentro del régimen de beneficios asistenciales y económicos (Delgado BernaL, 2012, p. 166).

Por último, en este orden jurídico normativo acerca de los antecedentes garantistas y procedimentales de la seguridad social se encuentra hoy la Ley 1438 de 2011, en la que se reforma el POS, se amplían los principios y características del Sistema de Seguridad Social en Salud, se regula la elección de directores o gerentes y la evaluación de planes de gestión, se determinan las medidas para la eficiencia y el fortalecimiento institucional de las empresas sociales del Estado, la formación del talento humano, el régimen de actuación y contratación de los trabajadores de la salud, el régimen sancionatorio, rectoría y organización institucional, salud pública, promoción y prevención, financiación y flujos de recursos (Cortés González, 2011, p. 39).

\subsection{Derecho a la salud y seguridad social en salud}

El Estado Social de Derecho trae consigo un conjunto de derechos sociales establecidos en la Carta Magna, uno de ellos es la segu- ridad social en salud. En ella se contempla su caracterización y especificidades fácticonormativas como un derecho constitucional, el cual es concebido según la Corte Constitucional:

(DERECHO A LA SALUD. Carácter prestacional/DERECHO A LA SEGURIDAD SOCIAL. Carácter prestacional, 1999). Según lo ha expresado la jurisprudencia constitucional, estos derechos son prestacionales propiamente dichos, para su efectividad requieren normas presupuestales, procedimientos y organización, que hagan viable el servicio público de salud y que sirvan, además, para mantener el equilibrio del sistema. La implementación de este servicio requiere, entre otros aspectos, de la creación de estructuras destinadas a atenderlos y de la asignación de recursos con miras a que cada vez un mayor número de personas acceda a sus beneficios. Por ello, en principio los derechos de contenido social, económico o cultural, no involucran la posibilidad de exigir del Estado una pretensión subjetiva. Empero, la jurisprudencia de la Corte ha sido reiterativa en manifestar que "la condición meramente programática de los derechos económicos, sociales y culturales tiende a transmutarse hacia un derecho subjetivo, en la medida en que se creen los elementos que le permitan a la persona exigir del Estado la obligación de ejecutar una prestación determinada, consolidándose entonces (el deber asistencial), en una realidad concreta en favor de un sujeto específico". 
Bajo estos parámetros y con una visión focalizada con respeto a las diferencias pragmáticas, epistemológicas, jurídicas y fácticas entre derecho a seguridad social en salud y derecho a la salud, los cuales suelen confundirse por el mundo de las ciencias jurídicas y asistenciales, porque en el mundo de la importancia de los derechos sustanciales enfrentados con los asuntos procesales se debe tener claridad del bagaje teórico de precisiones, que define la Corte Constitucional de la siguiente forma:

(DERECHO A LA SALUD. Presupuestos a cumplir para considerarlo fundamental/ DERECHO A LA SEGURIDAD SOCIAL. Presupuestos a cumplir para considerarlo fundamental) Una de las hipótesis en que los derechos a la Seguridad Social y a la salud cambian su carácter programático, e involucran el poder para exigir del Estado el derecho a la atención, es la del afiliado a una entidad de Seguridad Social. Empero, en ese caso, para que los derechos a la Seguridad Social o a la salud se consideren como derechos fundamentales, es necesario que cumplan los presupuestos destacados por la jurisprudencia de la Corte: "primero, que opere en conexión con otro derecho fundamental; segundo, entendida como la asistencia pública que debe prestarse ante una calamidad que requiera, de manera grave e inminente la vida humana o la salud; tercero, ante casos de extrema necesidad, y cuanto, que se pueda prestar de acuerdo con las posibilidades reales de protección de que disponga el Estado para el caso concreto".
Conviene advertir que la Corte en esta sentencia describe los requisitos de los derechos a la seguridad social o a la salud para ser considerados fundamentales y los resume en que deben operar conexos con otro derecho fundamental; la asistencia pública debe prestarse ante una calamidad que ponga en peligro la vida o salud humana y que, en casos de extrema necesidad, el Estado la pueda ayunar conforme a sus posibilidades reales de protección, aspectos que el autor considera que no se atemperan con la realidad social del país, porque el acceso a la salud no es totalmente gratuito y la atencion mínima esencial es prácticamente sectorizada y estratificada, de modo que quien no tiene los medios no recibe atención médica.

(DERECHO A LA SALUD. Derecho fundamental per se/DERECHO A LA SALUD. Rasgo de la fundamentabilidad/DERECHO A LA SALUD. Derecho fundamental autónomo en sujetos de especial protección constitucional/DERECHO A LA SALUD-Fundamental por conexidad, 1999) Del principio de universalidad en materia de salud se deriva primordialmente el entendimiento de esta Corte del derecho a la salud como un derecho fundamental, en cuanto el rasgo primordial de la fundamentabilidad de un derecho es su exigencia de universalidad, esto es, el ser un derecho predicable y reconocido para todas las personas sin excepción, en su calidad de seres humanos con dignidad. En virtud del entendimiento del derecho a la salud como un derecho constitucional con vocación de 
universalidad y por tanto de fundamentabilidad, esta Corte en su jurisprudencia, ha resaltado la importancia que adquiere la protección del derecho fundamental a la salud en el marco del estado social de derecho, en cuanto afecta directamente la calidad de vida. También, la Corte Constitucional ha sostenido que el derecho a la salud eventualmente puede adquirir el estatus de derecho fundamental autónomo, tal es el caso del derecho a la salud de los niños, de las personas de la tercera edad, o sujetos de especial protección constitucional por lo que no hay necesidad de relacionarlo con ninguno otro para que adquiera tal status, al igual que por conexidad con otros derechos fundamentales. De forma progresiva, la jurisprudencia constitucional ha reconocido del derecho a la salud su carácter de derecho fundamental considerado en sí mismo.

En un viraje diametral de su anterior línea jurisprudencial la Corte sostiene en esta decisión que la protección del derecho fundamental a la salud en el marco del Estado Social de Derecho afecta directamente la calidad de vida, es un derecho fundamental autónomo, cuando se trata de los niños, de las personas de la tercera edad, o sujetos de especial protección constitucional, cambiando de esta forma el criterio conservador y antiproteccionista desarrollado en la jurisprudencia de 1999. Se concibe que es esta la verdadera línea teleológica que debe inspirar siempre a todos los fallos judiciales que se hayan producido y se produzcan en la materia.

\subsection{Debido proceso en el derecho procesal de la seguridad social en salud}

El debido proceso también es llamado principio de reserva o legalidad. A nivel internacional, lo desarrollan los artículos 7 y 8 de la Declaración de los Derechos del Hombre, 10 y 11 de la Declaración Universal de los Derechos Humanos, y también el Pacto de los Derechos Civiles y Políticos (Vallejo Cabrera, 2009, pp. 41-42).

El debido proceso es un mandato inexcusable que no puede desatender las dependencias del Estado en sus distintos niveles de jerarquía, tanto en el sector central como en el descentralizado y en todas las ramas del poder público y organismos de control respecto de las actuaciones de sus correspondientes órbitas de competencia, so pena de incurrir en flagrante violación de la preceptiva constitucional y en ostensible abuso de sus atribuciones en detrimento de los derechos fundamentales, ocasionando a la vez la nulidad de las decisiones adoptadas con infracción de los preceptos superiores (Corte Constitucional. Sentencia T-460 de 1992).

En la Constitución Política de Colombia está regulado el debido proceso en los artículos 29 y 116; y lo referente a la Seguridad Social en Salud (SSS) en el Art. 49 de la misma, como una forma de realización y eficacia sustantiva del Estado Social de Derecho, que se mide por su capacidad de satisfacer, a través de la prestación de los servicios públicos, las necesidades vitales de la población median- 
te el suministro de prestaciones concretas que tiendan a ellos y, consecuentemente, de lograr por esta vía la igualdad de las condiciones materiales de existencia de las personas (Restrepo Medina, 2011, p. 106).

Artículo 29. Constitución Política: El debido proceso se aplicará a toda clase de actuaciones judiciales y administrativas.

Artículo 116. Constitución Política: Artículo modificado por el artículo 1 del Acto Legislativo No. 3 de 2002.

Artículo 49. Constitución Política: Artículo modificado por el artículo 1 del Acto Legislativo 2 de 2009. La atención de la salud y el saneamiento ambiental son servicios públicos a cargo del Estado.

En conformidad con lo antes mencionado, se puede decir que los artículos indican que para que haya un debido proceso en las actuaciones del procesal y la SSS de acuerdo a la nueva visión del Derecho contemporáneo a partir de las controversias o conflictos que dirime esta jurisdicción, el juez competente (natural) deberá tener un conocimiento amplio y preciso del complejo normativo de la SSS, tales como la Ley 10 de 1990, Ley 100 de 1993, Decreto 806 de 1998, Ley 712 de 2001, Ley 715 de 2002, Ley 691 de 2006, Decreto 1011 de 2006, Ley 1122 de 2007, Leyes 1437 y 1438 de 2011. Y deberá desplegar bajo los mecanismos y procedimientos previamente establecidos un análisis y valoración ajustada a derecho.
Ahora bien, el hecho de que existan normas del debido proceso sobre la seguridad social en salud previamente establecidas, limitan al juez para que no pierda la directriz de valorar y juzgar los hechos sometidos a su competencia bajo otras ópticas que no sean las propias de este juicio, pues debe cumplir con la función y procedimiento respectivo, para que se constituya una verdadera garantía constitucional del debido proceso.

Bajo estos parámetros normativos y con una visión focalizada en el debido proceso en las actuaciones del derecho procesal de la seguridad social es claro que esta consiste no solo en la posibilidad de defensa o en la oportunidad para interponer recursos, sino que exige además, como lo expresa el artículo 29, el ajuste a las normas preexistentes y reglamentarias respecto a la prestación de los servicios en salud, y el derecho a una resolución que defina las cuestiones jurídicas planteadas sin dilaciones injustificadas, aunque no existan normas procesales especiales que rijan los procedimientos en materia de SSS; considerando que los conflictos que se dirimen en esta jurisdicción principalmente son inherentes al derecho a la vida y al pleno restablecimiento de las contingencias que lleguen a surgir.

\subsection{El derecho procesal de la seguridad so- cial en salud}

Ahora bien, los procedimientos judiciales en seguridad social en salud tienen por objeto restablecer el orden del sistema en cuanto a 
la prestación de los servicios en consonancia con las características y principios específicos (Tono Ramírez, 1997, p. 44). Estos lineamientos o preceptos dogmáticos están establecidos en el artículo 153 de la Ley 100 de 1993 y en la Ley 1438 de 2011, los cuales son de universalidad, solidaridad, igualdad, obligatoriedad, prevalencia de derechos, enfoque diferencial, equidad, calidad, eficiencia, participación social, progresividad, libre escogencia, sostenibilidad, transparencia, descentralización administrativa, complementariedad y concurrencia, corresponsabilidad, irrenunciabilidad, intersectorialidad, prevención, continuidad (Delgado Bernal, 2012, p. 329).

Atendiendo a las consideraciones antes señaladas con respecto a la finalidad que persiguen los procedimientos jurisdiccionales en materia de la seguridad social en salud, los cuales están inspirados en sus principios, características y reglas propias señaladas en los compendios normativos acerca de las contingencias y prestaciones cubiertas o atendidas por el sistema, esto connota la autenticidad, especificidad y especialidad que tienen dichos procedimientos. Para explicar esto en el ámbito del mundo procesalista se pueden citar los aportes de Pasco Cosmopoli, citado por Silva Romero, Enseñanza del derecho procesal del trabajo (2011, pp. 321325), quien, en sus cursos de solución de conflictos de la seguridad social, desarrolla las siguientes escuelas:

Escuela del Proceso Único: considera que el
Código Civil consagra derechos sustantivos y procesales, y es la columna vertebral de las sociedades latinas, razonando que todos los conflictos se pueden solucionar, aplicando el Código Civil, ya que contiene soluciones sencillas y prácticas y así entenderíamos, que por permanecer durante muchos siglos, conllevó a la dictadura del proceso civil. En el siglo XXI, aparece el debilitamiento del proceso civil, y se han especializado los procedimientos en especial el procedimiento laboral y que aplica a los conflictos que surgen de la seguridad social y de la aplicación de sus principios rectores, las consideraciones principales del proceso único.

Escuela de la Autonomía Moderada: considera que el derecho procesal es uno solo pero que se hace necesario un código específico, especializado, que contenga instituciones propias del trabajo, y aquellos vacíos que se presenten serán llenados por "remisión", al Código Civil.

Escuela Radical: considera que se tiene que hablar de solución a conflictos laborales, y la solución de los mismos se parte del criterio de igualdad de las partes y las distribución de la carga de la prueba y la solución de los conflictos laborales deben resolverse en equidad y que su trámite no tiene que ver con las instituciones auténticas.

Escuela de la Autonomía Avanzada: su sustentación central se podría resumir en los principios reales que inspiran los pro- 
cedimientos laboral o el procesal laboral, que son el de veracidad o de prevalencia del fondo sobre la forma, con institutos, principio protector, o de desigualdad compensatoria y principio de criterio de conciencia en la exégesis de la prueba y equidad en la resolución.

Como se ha podido observar anteriormente, existen cuatro escuelas que pretenden explicar la especialidad y singularidades en que se pueden encasillar los procedimientos de la seguridad social en salud, pero la que mayor muestra la independencia conceptual, teórica y epistemológica a que se refiere o en que está cimentado el Sistema de Seguridad Social en Salud es la de la autonomía avanzada, donde se indican principios de exclusividad en la materia; ello lleva a decir, que todo el procedimiento está construido a partir de lo sustancial.

Con base en lo expuesto, cabe señalar que el derecho sustancial frente al procesal tiene una prevalencia de índole constitucional, haciendo posible una protección judicial efectiva, según Ramírez Carvajal (2010, p. 24), taxativamente manifiesta:

El derecho fundamental al debido proceso surge como un conjunto de principios que se encuentran en el artículo 29 de la Constitución Política de Colombia, pero, a su vez, el debido proceso ha de entenderse como parte de una macro estructura que se denomina la tutela judicial efectiva; el conjunto de principios constitucionales, lo que integran el debido proceso como columna cardinal del derecho procesal contemporáneo es lo que permite sostener que el derecho procesal supera, no abandona, su función instrumental, para elevarse a esferas en el componente del sistema de garantías y expedita de sus derechos.

Así mismo, autores como Pinilla Campos (2011), establecen un análisis de relación entre el derecho sustancial por encima del formal, la constitucionalidad del derecho procesal de la seguridad social y los fines esenciales del Estado Social de Derecho cuando expresa:

Cuando se trata de un sistema jurídico, éste debe interpretarse siempre acorde a la Carta política haciendo descender sus valores, principios y reglas a todo el resto de la normatividad $y$, por consiguiente en lo que respecta al derecho de la Seguridad Social y a sus correspondientes reglas de derecho procesal, la filosofía que emana de la fórmula política, es decir del Estado Social de Derecho que, como se verá, ha deslindado campos filosóficos del clásico Estado Liberal (p. 89).

En esta secuencia lógica de ideas, cabe decir que lo sustancial está ligado con la Constitución, desde múltiples ángulos o aristas de la seguridad social en salud, ya que este es un derecho constitucional, un sistema, una política pública, servicio público esencial, instrumento o una herramienta (Arenas Monsalve, 
2009, p. 167). Quiere decir lo anterior que el derecho laboral nace de un origen netamente constitucional, tiene fines de política estatal y se convierte en un mecanismo para hacer efectivo, como un derecho fundamental de las personas, este servicio público de carácter esencial.

\section{CONCLUSIÓN}

De acuerdo con los razonamientos expuestos en este producto investigativo, se colige que si bien existe la Constitución Política como norma de normas y se han legislado una serie de normatividades concretas en materia de seguridad social en salud, se hace necesario que prevalezca el derecho sustancial, para garantizar el acceso a una cumplida administración de justicia, que pueda dirimir las diferencias que surjan de las contingencias de enfermedad y maternidad, que son hechos biológicos futuros y ciertos y que se adecúe el procesal laboral al procesal de la seguridad social como un derecho integral e integrador, que garantice el mínimo de derechos y el debido proceso.

Si bien existe por ordenamiento legal una jurisdicción a la que se le ampliaron sus competencias en los temas de la seguridad social en salud -al igual que en la Superintendencia de Salud con sus facultades jurisdiccionales y los juzgados administrativos con la Ley 1437 de 2011- haciéndola específica, esta no ha sido suficiente para solucionar el caos que se presenta al valorar los factores de competencia de acuerdo a la naturaleza del demandan- te y la naturaleza jurídica de la demandada, a lo complejo de los hechos y pretensiones de los temas sometidos al juzgamiento, porque muchas veces no cumplen con la finalidad de su creación, que es proferir fallos ajustados al derecho, generándose así conflictos por factores de competencia que no subsistieran si existiera una JURISDICCIÓN ESPECIAL DE LA SEGURIDAD SOCIAL que conociera especialmente de los temas de pensiones, riesgos profesionales y salud.

\section{REFERENCIAS}

Almansa Pastor, J. M. (1984). Derecho a la seguridad social. Madrid: Tecnos.

Álvarez Pereira, C. \& Dacosta Herrera, A. F. (2011). La enseñanza de la constitucionalización del derecho del trabajo y de la seguridad social. En M. Silva Romero, Reaprender la enseñanza del derecho del trabajo y de la seguridad social. Bogotá, D.C.: Kimpres Ltda.

Arenas Monsalve, G. (2009). El derecho colombiano a la seguridad social. Bogotá: Legis.

Bustamante Rua, M. M. (2010). Derecho procesal contemporáneo. Medellín: Sello Editorial.

Carnelutti, F. Instituciones del proceso civil. Buenos Aires: Jurídica Europa-América.

Cortés González, J. C. (2011). Reforma al sistema de salud. Bogotá: Legis. 
Delgado Bernal, C. I. (2012). Código Sutantivo del Trabajo y Código Procesal del Trabajo y la Seguridad Social. Bogotá: Legis.

Delgado, J. M. (1994). Métodos y técnicas cualitativas de investigación en Ciencias Sociales. Madrid: Síntesis.

Durand, P. (1991). La política contemporánea de la seguridad social. En M. D. Social, Madrid: Ministerio de Trabajo y Seguridad.

Fernández Sierra, J. A. (2009). Práctica judicial en el Sistema de Seguridad Social en Salud. Bogotá: Escuela Judicial Rodrigo Lara Bonilla.

Henríquez Ureña, P. (1979). Historia de la cultura en la América Hispánica. México: Fondo de Cultura Económica.

Hernández Sampieri, R. (2007). Metodología de la investigación. México: McGraw-Hill.

Herrera Ramírez, F. J. (2005). Manual de responsabilidad médica. Bogotá: Leyer.

Liévano Aguirre, I. (1895). Los grandes conflictos sociales y económicos de nuestra historia. Bogotá: Tercer Mundo.

López Medina, D. E. (2004). Nuevas tendencias en la dirección de proceso. Módulo de formación. Plan Nacional de Formación y Capacitación de la Rama Judicial.
Mercado Jaraba, E. E. (2010). Práctica judicial en el proceso ejecutivo laboral. Bogotá: Escuela Judicial Rodrigo Lara Bonilla.

Obando Garrido, J. M. (2007). Derecho laboral. Bogotá D.C.: Tunvimor.

Pabón Giraldo, L. (2010). Competencia. En D. Ramírez Carvajal, Derecho procesal contemporáneo (pp. 177-208). Medellín: Universidad de Medellín.

Peña Peña, R. (2007). Constitución comentada. Bogotá: Ecoe Ediciones.

Pérez Rivera, P. H. (1997). Sistemas nacionales de seguridad social. Medellín.

Pinilla Campos, E. (2011). Teoría del derecho procesal del trabajo en la Constitución Política. Conceptos esenciales para su comprensión y aplicación. En Manual de derecho laboral (pp. 75-130). Bogotá: Universidad Externado de Colombia.

Quintero, B. y. (2000). Teoría general del proceso. Bogotá: Temis.

Ramírez Carvajal, D. (2010). La polarización entre el derecho sustancial y el derecho procesal. Medellín: Universidad de Medellín.

Rengifo O., J. M. (1989). La seguridad social en Colombia. Bogotá: Temis.

Restrepo Medina, M. (2011). La Constitución al alcance de todos (pp. 117, 118). Bogotá: Nomos Impresores. 
Rodríguez Moreno, R. \& Rodríguez Pineda, A. (1985). Derecho procesal civil. Procesos de ejecución, Tomo II. Edición IV, V. Bogotá: Temis.

Ruiz Orjuela, W. (2010). Responsabilidad del Estado y sus regímenes. Bogotá: Ecoe Ediciones.

Silva Romero, M. (2011). Enseñanza del derecho procesal del trabajo. En M. Silva Romero, Reaprender la enseñanza del derecho al trabajo y la seguridad social (pp. 304-344). Bogotá: Kimpres Ltda.

Soto Soto, O. (2010). El proceso jurisdiccional. En D. Ramírez Carvajal, Derecho procesal contemporáneo (pp. 241-312). Medellín: Universidad de Medellín.

Tirado Díaz, N. (2007). Sistema de Seguridad Social en Salud. Escuela Judicial Rodrigo Lara Bonilla.

Tono Ramírez, M. T. (1997). Seguridad social en salud. En J. Blanco Restrepo, Fundamentos de salud pública (pp. 43-49). Medellín: Corporación para las Investigaciones Biológicas.

Uprimny Yepes, R. El derecho a la salud en la jusrisprudencia constitucional colombiana en la salud pública de hoy. Bogotá: Universidad Nacional de Colombia.

Vallejo Cabrera, F. (2009). La oralidad laboral teoría y práctica. Medellín: Sánchez R.
Acto Legislativo No. 3 de diciembre 19 de 2002.

Constitución Política de 1991, Arts. 1, 2, 3, $13,23,29,42,43,48,49,53,86,116,228$, 229.

Corte Constitucional, Sentencia C-088 de 2001.

Corte Constitucional, Sentencia C-463 de 2008.

Corte Constitucional, Sentencia T-1451 de 2000.

Corte Constitucional, Sentencia T-460 de 1992.

Corte Constitucional, Sentencia T-012 de 2012.

Decreto 806 de abril 30 de 1998.

Decreto 1382 de julio 12 de 2000.

Decreto 1011 de abril 03 de 2006.

Decreto Ley 2350 de 1944.

Decreto Ley 2158 de junio 24 de 1948 "Código Procesal del Trabajo y de la Seguridad Social", Arts. 2, 30, 77, 100.

Demanda en contra de ESE por fallas en el Servicio de Salud, 15563 (Consejo de Estado, 20 de febrero de 2008). 
Derecho a la Salud. Carácter prestacional/ Derecho a la Seguridad Social, Sentencia SU819/99 (Corte Constitucional, 20 de octubre de 1999).

Gaceta Judicial LIV (Corte Suprema de Justicia, 31 de agosto de 1942).

Ley 270 de marzo 07 de 1996, Art. 85.

Ley 362 de febrero 18 de 1997.

Ley 712 de diciembre 08 de 2001, Art. 2

Ley 691 de septiembre 18 de 2001.

Ley 715 de diciembre 21 de 2002.

Ley 1122 de enero 09 de 2007.

Ley 1149 de julio 13 de 2007, Art. 11.
Ley 1438 de enero 19 de 2011.

Ley 1564 de julio 12 de 2012 "Código General del Proceso", Art. 622.

Sistema De Seguridad Social en Salud. Está diseñado para asegurar cobertura integral y mejorar calidad de vida de población/Sistema de Seguridad Social en Salud. Protección integral, T-518-06 (Corte Constitucional, 7 de julio de 2006).

Sistema de Seguridad Social en Salud. Prestación por particulares en condiciones de libre competencia, Sentencia C-616/01 (Corte Constitucional, 13 de junio de 2001).

Sistema General de Seguridad Social en Salud. Amplio margen de configuración legislativa, Sentencia C-869/10 (Corte Constitucional, 2010).

Ley 1395 de julio 12 de 2010. 